\title{
Rheumatoid Arthritis Association and SS Drepanocytosis about Observation at Kati Military Hospital Infirmeria (IHK)

\author{
Sanogo A ${ }^{1}$, Diaby LM ${ }^{2 *}$, Diallo L ${ }^{4}$, Camara $\mathrm{Y}^{4}$, Diarra L ${ }^{3}$, Maiga A. $\mathrm{S}^{1}$, Diakite $\mathrm{Y}^{5}$
}

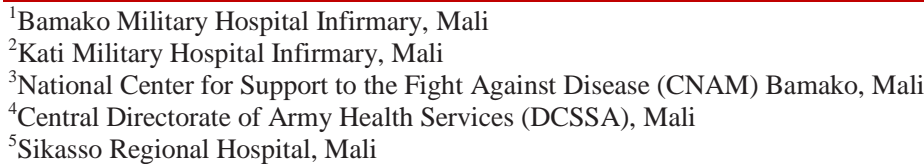

${ }^{3}$ National Center for Support to the Fight Against Disease (CNAM) Bamako, Mali

${ }^{4}$ Central Directorate of Army Health Services (DCSSA), Mali

${ }^{5}$ Sikasso Regional Hospital, Mali

*Corresponding author: Diaby LM

Abstract

Introduction: Rheumatoid arthritis (RA) with a prevalence of 0.3 to $1 \%$ in the adult population is a chronic systemic inflammatory disease characterized by proliferative synovitis (pannus) leading to osteocartilaginous destruction leading to joint deformities [1]. The aim of this study is to show rheumatoid arthritis masked by sickle cell disease. Observation: This is a 38-year-old male, Soninke, 38-year-old female patient with known sickle cell disease who had consulted for polyarticular pain and lameness. In clinical and paraclinical studies, the diagnosis of rheumatoid arthritis was made in accordance with the ACR / EULAR 2010 criteria for sickle cell disease confirmed by hemoglobin electrophoresis. Conclusion: Rheumatoid arthritis is a common connective tissue disease in women. Its association with sickle cell disease is rare and can be a source of error or delay in diagnosis.

Keywords: Polyarthritis, sickle cell anemia, hemoglobinopathies.

Copyright $(\mathcal{C} 2021$ The Author(s): This is an open-access article distributed under the terms of the Creative Commons Attribution 4.0 International License (CC BY-NC 4.0) which permits unrestricted use, distribution, and reproduction in any medium for non-commercial use provided the original author and source are credited.

\section{INTRODUCTION}

Rheumatoid arthritis (RA) with a prevalence of 0.3 to $1 \%$ in the adult population, is a chronic inflammatory systemic disease characterized by proliferative synovitis (pannus) which leads to osteocartilaginous destruction resulting in joint deformities [1]. It can appear on pre-existing defects with osteo-articular manifestations leading to misdiagnosis and making treatment difficult. Rheumatoid arthritis (RA) is a co-morbid condition in patients with sickle cell anemia.

Sickle cell disease is an inherited, codominant, autosomal recessive disease characterized by the presence of abnormal hemoglobin (Hbs) in the blood [2]. It is a chronic disease in which certain forms progress to severe complications (acute anemia, splenic sequestration, erythroblastopenia, vaso-occlusive crises, etc.) [2]. In Mali, the prevalence of sickle cell disease is estimated at $12 \%$ on average, including 1 to $3 \%$ for the homozygous form [2].

Hereditary genetic diseases such as hemoglobinopathies are manifested by osteoarticular manifestations from birth and may mask the onset and course of rheumatoid arthritis in these patients [2].

Corticosteroid therapy is one of the symptomatic treatments for rheumatoid arthritis at the same time as it is a contraindication in cases of hemoglobinopathy, particularly sickle cell anemia, where it can worsen or promote bone necrosis [3]. Symptomatic treatment of patients therefore remains primarily the use of non-steroidal anti-inflammatory drugs and analgesics [4].

The objective of this study is to show rheumatoid arthritis masked by sickle cell disease.

\section{OBSERVATION}

This is a black patient, of Soninké ethnicity, 38 years old married with known sickle cell disease who had consulted for polyarticular pain and lameness.

Physical examination revealed chronic, polysynovial, bilateral, symmetrical, peripheral, distal non-ankylosing and deforming polyarthritis with a 07/10 VAS, MD greater than 1 hour; NAD: 14, NAG: 6. Else where there was complete insomnia associated 
with diffuse bone pain. The review of the other devices was unremarkable.

Faced with this clinical picture, we requested additional examinations, the results of which are as follows:

- Blood count: inflammatory anemia (Hb: 9g / 1), VS and CRP increased, protein electrophoresis showed polyclonal hypoalbuminemia, hyper alpha, hyper gamma,

- Electrophoresis of hemoglobin found sickle cell anemia form SS.

- Rheumatoid factor (RF) positive at $161 \mathrm{IU}$ and anti citrullinated peptide (CCP) antibody at 199 IU,

- On the face X-ray of the wrists and hands, we noted demineralization in the apophyseal band, bilateral carpitis, erosion of the fifth head on the right.

- The pre-therapeutic assessment (AgHBS; HIV, transaminases; creatinine, urea) was normal.

Based on clinical and paraclinical data, the diagnosis of rheumatoid arthritis was made in accordance with the ACR / EULAR 2010 criterion associated with sickle cell disease confirmed by electrophoresis of hemoglobin.

The patient was put on:

- Methotrexate injection $25 \mathrm{mg}$ in SC combined $15 \mathrm{mg}$ of folic acid per week,

- Prednisolone 10mg tablet combined with 500mg calcium and 200IU of vitamin per day,

- Tramadol $150 \mathrm{mg}$ per day,

- Cortisonic infiltration of four joints.

After two months of treatment there was a marked improvement in symptoms, NAD: 2, DM; EVA: 04/10; less than 15 minutes, the synovitis had disappeared, $\mathrm{Hb}$ at $11 \mathrm{~g} / \mathrm{l}$; a decrease in SV and CRP.

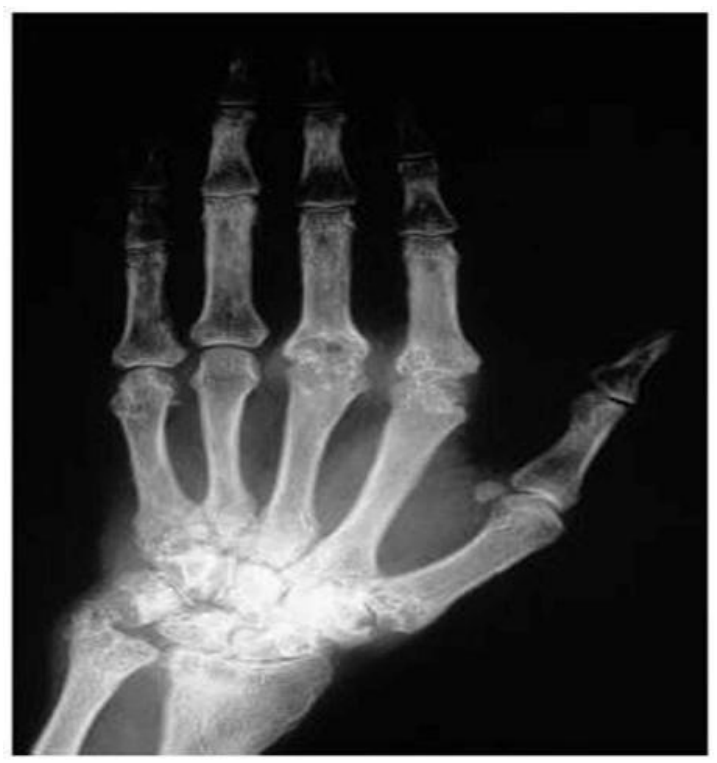

Fig-1: X-ray of the left hand Amount: geodes, erosion, pinching Carpite

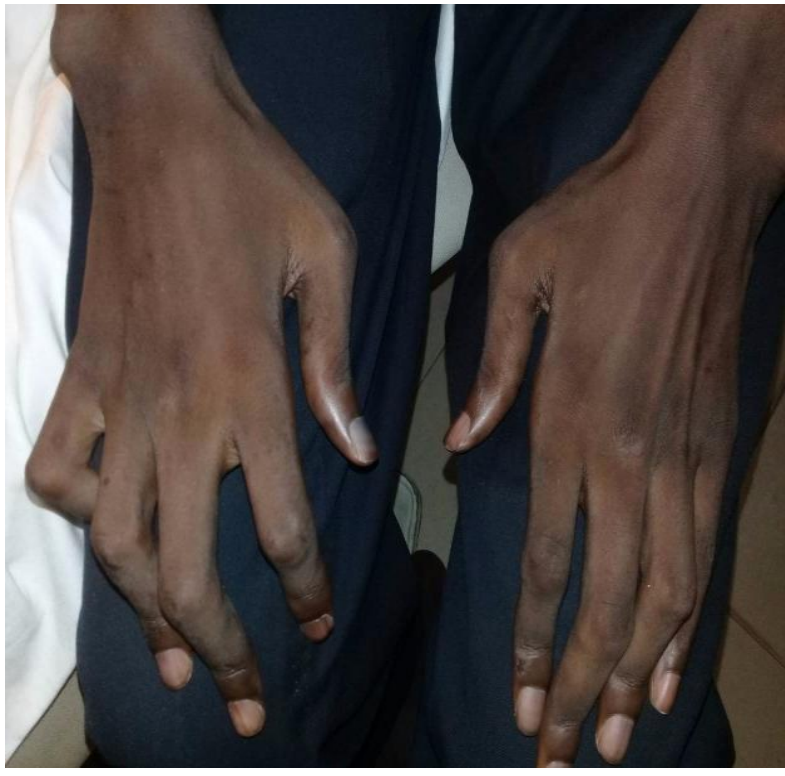

Fig-2: Image of deformities (swan neck)

\section{DISCUSSION}

The prevalence among patients with hemoglobinopathy is close to $4.3 \%$ estimated by Ouédraogo in Burkina [1]. The occurrence of RA in patients with hemoglobinopathy seems relatively more frequent than the prevalence of RA in the general population [5], unlike our study. However, joint involvement could lead the diagnosis to err in the direction of a manifestation of hemoglobinopathy and confuse the two diagnoses in agreement with the arguments of Fifi-Mah et al., that the association of RA and sickle cell disease is rare [6].

However, the polyarticular disease from the outset affecting mainly large and small joints in patients could confuse certain RA pains to a painful sickle cell crisis. Any inflammatory outbreak can be a source of sickle cell crisis.

Corticosteroid therapy is one of the pillars of the symptomatic treatment of rheumatoid arthritis at the same time as it is a contraindication in cases of hemoglobinopathy, particularly sickle cell anemia where it can worsen or promote bone necrosis [5]. Symptomatic treatment of patients therefore remains primarily the use of non-steroidal anti-inflammatory drugs and analgesics [6].

The disease-modifying treatment of rheumatoid arthritis in the African context is based on the use of methotrexate in combination with folic acid despite the existence of biotherapy. This choice is due to the inaccessibility and cost of biotherapies. In our observation, methotrexate showed its effectiveness after two months of treatment despite the combination of RA and sickle cell disease. 
According to the Beninese study which shows the rheumatological benignity of $\mathrm{AS}, \mathrm{AC}$ and $\mathrm{CC}$ hemoglobinopathies. Any epiphyseal osteonecrosis in black Africa should first be investigated for major sickle cell syndrome (SS or SC) [6].

We find here that despite an autoimmune disease associated with hemoglobinopathy, functional prognosis and complications can be avoided with early detection and adequate specialized management.

\section{CONCLUSION}

Rheumatoid arthritis is a common connectivitis in women who are genitally active. Its association with sickle cell anemia is rare and may be a source of error or delay in diagnosis. This association can cause functional and vital complications.

Good rheumatologist-hematologist collaboration is necessary for the proper management of patients whose treatment remains delicate due to iatrogenic complications.

\section{REFERENCES}

1. Ouédraogo DD, Nacoulma EW, Kafando E, Ouédraogo A, Tiéno H, Koulidiaty J, Drabo JY.
Pathologies rhumatologiques et

hémoglobinopathies à Ouagadougou (Burkina Faso). Bulletin de la Société de pathologie exotique. 2010 May 1;103(2):80-3.

2. Doumbia A. Aspects epidemio-cliniques des enfants drépanocytaires suivis en pédiatrie, Thes Med FMPOS, Bamako, 2009; 1-3.

3. Jean-Baptiste G, De Ceulaer K. Actualité des manifestations rhumatologiques des hémoglobinopathies. Revue du rhumatisme (Ed. française). 2003;70(2):157-61.

4. Brunier L, Bleterry M, Merle S, Derancourt C, Polomat K, Dehlinger V, Deligny C, Jean-Baptiste G, Arfi S, Banydeen R, De Bandt M. Prevalence of rheumatoid arthritis in the French West Indies: results of the EPPPRA study in Martinique. Joint Bone Spine. 2017 Jul 1;84(4):455-61.

5. Zomalhèto Z, Baglo T, Gounongbé T. Association polyarthrite rhumatoïde et drépanocytose au sein de la population béninoise: difficultés diagnostiques et thérapeutiques formation médicale continue-observation clinique, le rhumatologue / février 2018, 28-30.

6. Fifi-Mah A, Jean-Baptiste G, Arfi S. Polyarthrite rhumatoïde et drépanocytose: une association rare. Rev rhum. 1999;66:104. 